\title{
Base shear variation for irregular $G+6, G+9$ and $G+12$ structures in seismic zones IV and V for three soil types
}

\author{
Vanadeep Cotipalli \\ Assistant Professor, GRIET, Hyderabad 500090, India
}

\begin{abstract}
It is attempted to expand upon the understanding on the structure's behaviour when the seismic force, which is one of the predominant lateral forces, is applied on the structure. The base shear is calculated and compared for various variable parameters. For the three soil types the base shear is contrasted while varying the building heights of an irregularly planned structure in the seismic zones: IV and V. The structures' heights are taken as follows: $\mathrm{G}+6, \mathrm{G}+9, \mathrm{G}+12$ and storey height as $3 \mathrm{~m}$. Concluded observations talks about the amount of the variation in the base shear when the structure height and soil types are altered. While the $\mathrm{G}+9$ and $\mathrm{G}+12$ structures behaved identically, the $\mathrm{G}+6$ structures in the medium and the soft soils fetched same results.
\end{abstract}

\section{Introduction}

Since the computation got easy as well as cheaper the research has developed exponentially in the field of Engineering, especially in the designing field. This helped us understand the behaviour of any structure in civil engineering industry. The research also has grown as the result. The very fundamental goal in designing is to attain the economy in usage of the materials along with the safety from the unpredictable loadings. This results in cost reduction and robust structures in terms of safety. Numerical modelling using a software could help us understand the structures behaviour when there are several loads such as wind loads and earthquake loads. What causes an earthquake? The shaking of earth generally occurs as a result of the releasing of suppressed energy within the earth's crust. From the lithosphere of the earth the energy released produces different types of waves on the surface of the earth and these waves would result in the earthquakes. Impact that earthquakes create on mankind could be unimaginably horrifying as it would result in loss of life, property and hope. As it could be very deadly, accounting for these forces during the design would help tremendously for any society. In lateral equivalent static force method, the base shear is calculated and studied for any structure. The base shear is the lateral force that is generated at the base of the structure in the direction of earthquake. This base shear would alter depending upon the storey height of the building as well as the soil types and also on the intensity of the earthquake. In this study the three building heights are taken and analyzed for three different soil conditions in the IV and V seismic zones of the country. M. Dipak Kolekar and M. Mukund Pawar has made us understood that the change in the base shear and storey shear when the architectural plan as well as building height has been changed for different specific conditions takes place[1]. They can be determined by using a modelling software called STAAD Pro. Elastic equivalent lateral static force method can be used. Giru Mindaye, Dr. Shaik Yajdani has conducted a $\mathrm{G}+10$ building response is analyzed in this study when there is a lateral seismic loading on the structure. OMRF RC frame has been opted to conduct the study over seismic zones II and III of our country [2]. But SMRF is also considered for other zones. Outcomes like storey force, displacements and storey drifts are calculated and compared for both static and dynamic methods. S.P. Bhattacharya, S.K. Chakraborty used a lump mass model for the study. This had varying mass and stiffness ratios. Due to changes in the mass and stiffness the variation in lateral forces distribution along the height are observed when there is a seismic action [3]. It had gathered that it is possible to influence the base shear and storey shear when the mass distribution and stiffness is proportionate. But, high mass and stiffness ratio would result in instability and also would show a greater amount of lateral forces and shear. This paper has extensively focused on studying the behaviour of structure for different parameters; soils and varying structure heights in the finite element software STAAD Pro.

\section{Methodology}

The method called the equivalent static lateral force has been adopted for extracting the base shear values and in turn the values of the horizontal forces structures at each of the storey levels [4-7]. In both the $\mathrm{X}$ and $\mathrm{Y}$ directions

\footnotetext{
*Corresponding author: vanadeep.cotipalli@gmail.com (Vanadeep Cotipalli)
} 
the method is applied to determine the required values of base shear.

The irregular plan which gives the irregularity in $\mathrm{x}$ and $\mathrm{y}$ directions are chosen. For the three different heights of $\mathrm{G}+6, \mathrm{G}+9$ and $\mathrm{G}+12$ are considered for the analysis. Soils considered are hard, soft and medium. And, the seismic zones considered are IV and V for the analysis [5]. The loading on structure is generated in accordance with Indian Standards IS 1893 (2002). Designed in STAAD Pro v8i.

\subsection{Data corresponding to the Structure}

Parameters used in the modeling of the building are furnished in the following table titled Table.1.

Corresponding geometrical parameters are in the Figure.1

Table 1. Structure related Data

\begin{tabular}{|c|c|}
\hline Parameters & Description \\
\hline $\begin{array}{c}\text { Dimensions of beam } \\
(\mathrm{mm})\end{array}$ & $450 \times 300$ \\
\hline $\begin{array}{c}\text { Dimensions of } \\
\text { column (mm) }\end{array}$ & $450 \times 450$ \\
\hline Beam cover (mm) & 25 \\
\hline Column cover (mm) & 40 \\
\hline Storey & G+6, G+9 and G+12 \\
\hline Storey height (m) & 150 \\
\hline Slab (mm) & Fixed \\
\hline Supports & M30 and Fe415 \\
\hline Materials & \\
\hline
\end{tabular}

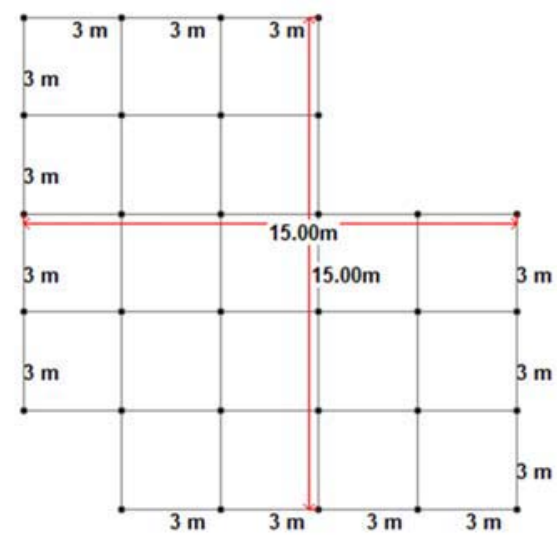

IRREGULAR
Fig. 1. Details of the plan

\subsection{Loading}

Following table is furnished with the data that talks of the loading on the structure in accordance with standards of IS 1893 (2002)

Table 2. Seismic-parameters

\begin{tabular}{|c|c|}
\hline Parameters & Description \\
\hline Dead Load (DL) & $3.75 \mathrm{KN} / \mathrm{m}^{2}$ \\
\hline Live load (LL) & $4 \mathrm{KN} / \mathrm{m}^{2}$ \\
\hline Roof Load & $2 \mathrm{KN} / \mathrm{m}^{2}$ \\
\hline Floor Finish & $1 \mathrm{KN} / \mathrm{m}^{2}$ \\
\hline Member Loading & $19 \mathrm{KN} / \mathrm{m}, 11 \mathrm{KN} / \mathrm{m}$ and $6 \mathrm{KN} / \mathrm{m}$ \\
\hline Frame type & $\mathrm{SMRF}$ \\
\hline Response reduction & 5 \\
\hline factor & 1 \\
\hline Importance factor (I) & $\mathrm{IV}, \mathrm{V}$ \\
\hline Seismic zones & Soft, Hard and Medium \\
\hline Type of soil & $5 \%$ \\
\hline Damping of structure & $\mathrm{X}$ and Z \\
\hline Earthquake directions & \\
\hline
\end{tabular}

\section{Results and discussions}

1. It can be seen that the value of the Base shear goes up for all the storey heights as there is increase in zone of earthquake from zone IV to zone $\mathrm{V}$.

2 . In the figures below, the observations can be seen that the base shear fetched is similar for $\mathrm{G}+6, \mathrm{G}+9$ and $\mathrm{G}+12$ for zones IV and V.

3. Similar to above medium soils the soft soils also has fetched the same values of base shear as can be seen in figure 3 .

4. For the hard soils, even though the trend remained same the values of base shear are relatively lower. 


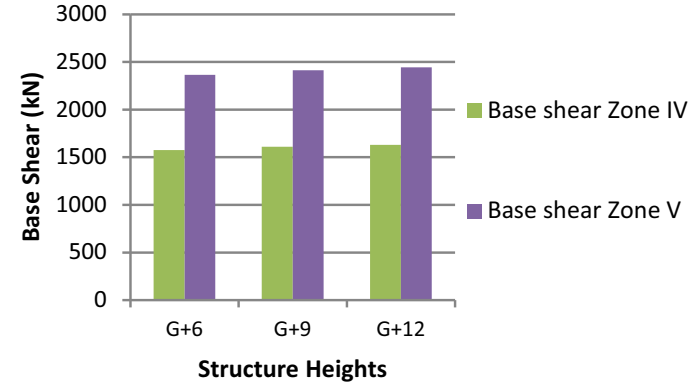

Fig. 2. Base Shear (Medium - Zone IV vs Zone V)

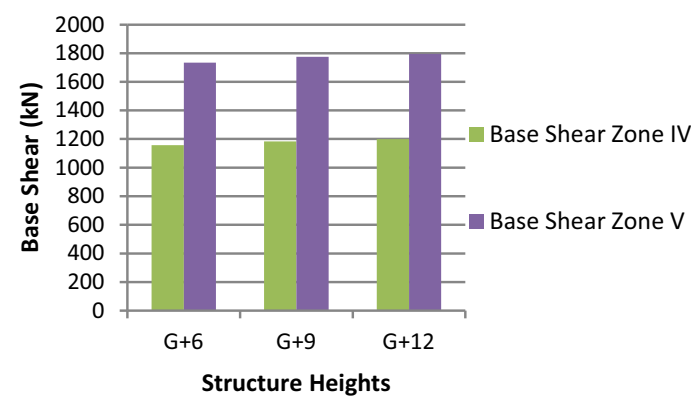

Fig. 3. Base Shear (Soft - Zone IV vs Zone V)

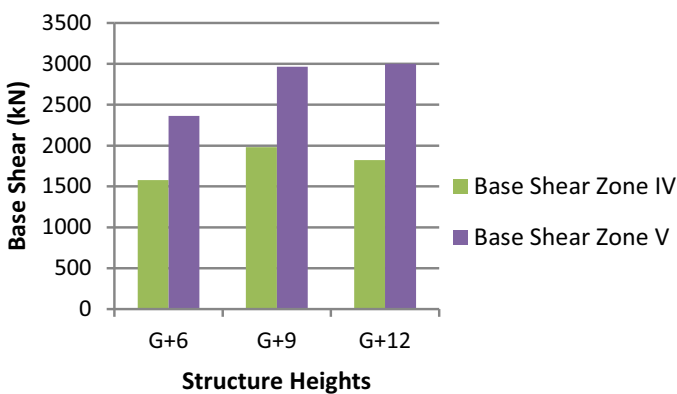

Fig. 4. Base Shear (Hard - Zone IV vs Zone V)

\section{Soil Comparison}

1. An observation can be made from the graphs of figure 5 , which says that the base shear value is the same for medium and soft soil types for the building height of $\mathrm{G}+6$. But the hard soils show $73 \%$ reduced base shear.

2. It is obsorved in figure 6 that in $\mathrm{G}+9$ structures the base shear in soft soils is $22 \%$ more than that in Medium soils Whereas it is $67 \%$ more when compared to hard soils. Unlike $\mathrm{G}+6$, in $\mathrm{G}+9$ the medium soils have $36 \%$ more base shear than that in hard soils.

3. But for $\mathrm{G}+9$ and $\mathrm{G}+12$ the pattern is same which is seen from the figure 7.

4. Along with the pictoric understanding of the values fetched, the same are noted and tabulated in the following tables corresponding to the graphs.

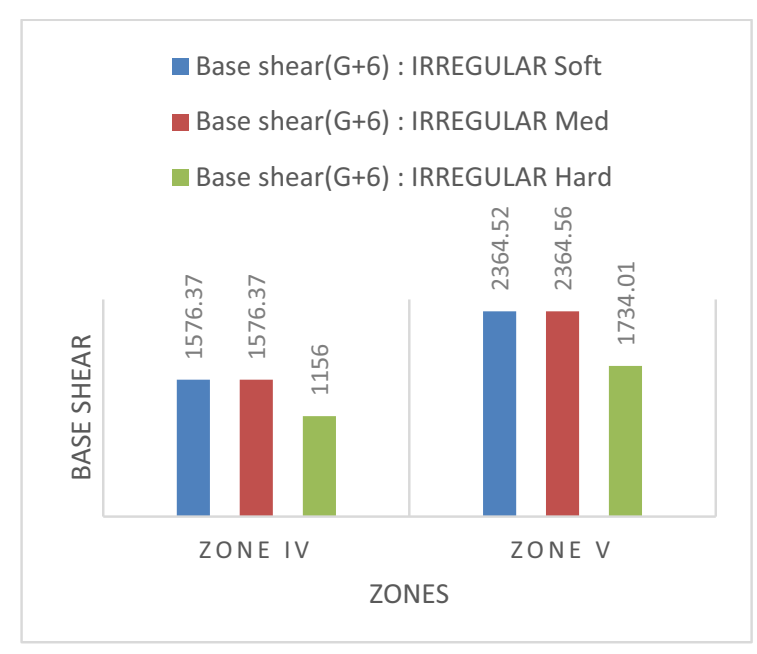

Fig. 5. Base Shear (Irregular - G+6 )

Table 3. Base Shear (Irregular - G+6)

\begin{tabular}{|c|c|c|c|}
\hline \multicolumn{4}{|c|}{ Base Shear (G+6) : IRREGULAR } \\
\hline & Soft & Med & Hard \\
\hline Zone IV & 1576.37 & 1576.37 & 1156 \\
\hline Zone V & 2364.52 & 2364.56 & 1734.01 \\
\hline
\end{tabular}

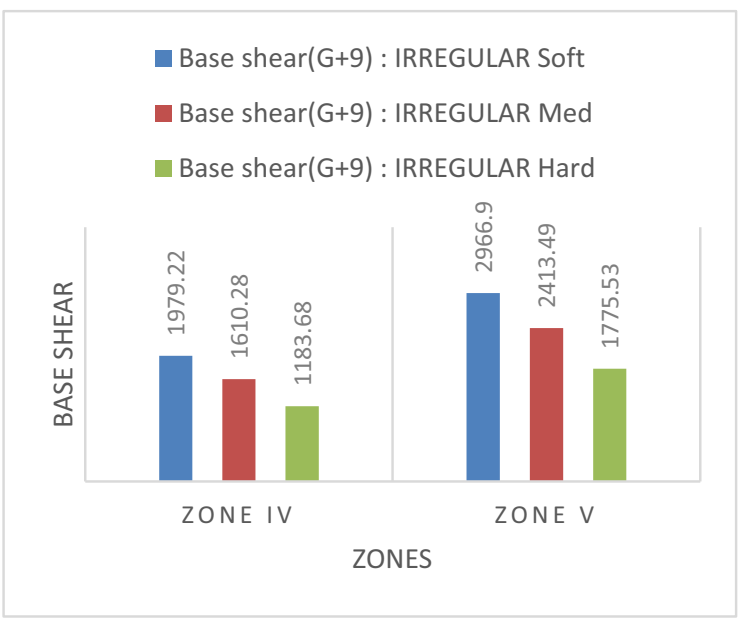

Fig. 6. Base Shear (Irregular - G+9)

Table 4. Base Shear (Irregular - G+9)

\begin{tabular}{|c|c|c|c|}
\hline \multicolumn{4}{|c|}{ Base Shear (G+9) : IRREGULAR } \\
\hline & Soft & Med & Hard \\
\hline Zone IV & 1979.22 & 1610.28 & 1183.68 \\
\hline Zone V & 2966.9 & 2413.49 & 1775.53 \\
\hline
\end{tabular}




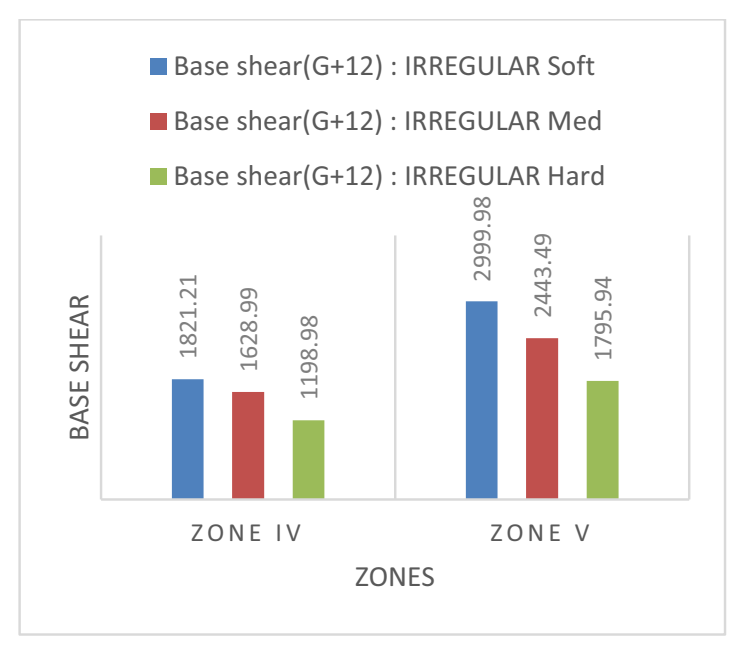

Fig. 7. Base Shear (Irregular - G+12)

Table 5. Base Shear (Irregular - G+12)

\begin{tabular}{|c|c|c|c|}
\hline \multicolumn{4}{|c|}{ Base Shear (G+12) : IRREGULAR } \\
\hline & Soft & Med & Hard \\
\hline Zone IV & 1821.21 & 1628.99 & 1198.98 \\
\hline Zone V & 2999.98 & 2443.49 & 1795.94 \\
\hline
\end{tabular}

\section{Conclusions}

- The value of the Base shear went up as there is change in zone of earthquake which is from zone IV to zone V.

- The base shear values remained almost same, for the $\mathrm{G}+6$ in soft and medium soils for both zones.

- For hard soils, in $\mathrm{G}+6$ structures, the reduction of $73 \%$ in base shear is determined compared to other soils.

- In G+9 structures, the base shear in soft soils has $22 \%$ more lateral force than that in medium soils. But, it is $67 \%$ more when compared to hard soils.

- In the medium soils, for $\mathrm{G}+9$, we have $36 \%$ more base shear than observed in hard soils.

\section{References}

1. M. Dipak Kolekar, M. Mukund Pawar Int J of Eng. Res. and Tech. 7, Issue 6 (2017)

2. Giru Mindaye, Dr. Shaik Yajdani, Int J of Innovative Res. in Sci., Eng. and Tech., Issue 9, (2016)

3. S.P. Bhattacharya, S.K. Chakraborty Int J Of Civil and Struct. Eng. 1, No 3, (2017)

4. Vanadeep Cotipalli, Vegiraju Naresh Kumar Varma, Uppuluri Praveen Kumar, today: Proceedings (2021)

5. V. Naresh Kumar Varma, Uppuluri Praveen Kumar, Today: Proceedings 37, (2021)

6. T. Srinivas, M. Abinay Raj, Int J of Eng. and Adv. Technol. 9, Issue-1, (2019)
7. T.Srinivas and M. Abinay Raj, Int. J. of Eng.and Adv. Tech. (IJEAT), ISSN: 2249 - 8958, Volume-8 Issue6 (2019)

8. T.srinivas and P. Manoj Anand, Int. J. of Innov. Tech. and Explor. Eng.g (IJITEE), ISSN: 2278-3075, Volume-8 Issue-12 (2019)

9. T.Srinivas and G. Sukesh Reddy, Int. J. of Eng.and Adv. Tech. (IJEAT), ISSN: 2249 - 8958, Volume-9 Issue-1 (2019)

10. T.Srinivas and R. N. Koushik, Int. J. of Innov. Tech. and Explor. Eng.g (IJITEE), ISSN: 2278-3075, Volume-8 Issue-12 (2019), PP 112-117.

11. K. Sai Gopi, Dr. T. Srinivas and S. P. Raju V, E3S Web of Conferences ICMED 184, 01084GRIET, 2829 February, https://doi.org/10.1051/e3sconf/2020184011084(202 $0)$

12. Jagannadha Kumar, M.V., Jagannadha Rao, K., Dean Kumar, B., Srinivasa Reddy, V., Int. J. of Civil Eng. and Tech., 9(7), pp. 1133-1141 (2018)

13. Ganta, J.K., Seshagiri Rao, M.V., Mousavi, S.S., Srinivasa Reddy, V., Bhojaraju, C., Structures 28, pp. 956-972 (2020)

14. Naidu, K.S.S.T., Rao, M.V.S., Reddy, V.S., Int. J. of Innov. Tech. and Explor. Eng.g (IJITEE), 8(9 Special Issue 2), pp. 641-642 (2019)

15. Chandana Priya, C., Seshagiri Rao, M.V., Srinivasa Reddy, V., Int. J. of Civil Eng. and Tech., 9(11), pp. 2218-2225 (2018)

16. Satya Sai Trimurty Naidu, K., Seshagiri Rao, M.V., Srinivasa Reddy, V., Int. J. of Civil Eng. and Tech., 9(11), pp. 2383-2393 (2018)

17. Supriya, Y., Srinivasa Reddy, V., Seshagiri Rao, M.V., Shrihari, S., Int. J. of Rec. Tech. and Engi., 8(3), pp. 5381-5385 (2019)

18. Kotkunde, N., Krishna, G., Shenoy, S.K., Gupta, A.K., Singh, S.K. International Journal of Material Forming, 10 (2), pp. 255-266 (2017)

19. Govardhan, D., Kumar, A.C.S., Murti, K.G.K., Madhusudhan Reddy, G. Materials and Design, 36, pp. 206-214. (2012)

20. Kumar, P., Singhal, A., Mehta, S., Mittal, A. Journal of Real-Time Image Processing, 11 (1), pp. 93-109. (2016)

21. Raghunadha Reddy, T., Vishnu Vardhan, B., Vijayapal Reddy, P. International Journal of Applied Engineering Research, 11 (5), pp. 3092-3102 (2016)

22. Hussaini, S.M., Krishna, G., Gupta, A.K., Singh, S.K. Journal of Manufacturing Processes, 18, pp. 151-158 (2015) 